\title{
PENGARUH FOCUS GROUP DISCUSSION TENTANG PELAKSANAAN UJI KOMPETENSI TERHADAP TINGKAT KECEMASAN MAHASISWA
}

\author{
Benny Andreson Situmorang ${ }^{1}$, Kristina L Silalahi ${ }^{2}$ \\ 1,2 Universitas Prima Indonesia, Indonesia \\ Email: bennyandreson@unprimdn.ac.id ${ }^{1} ;$ kristinasilalahi@unprimdn.ac.id $^{2}$
}

\begin{abstract}
The Indonesian National Competency Test (INCT) is carried out with the aim of equalizing the quality standards of graduates at each educational institution. For INCT students is a challenge that must be faced because to apply for a job a health worker must have a registration certificate $(R C)$. The registration certificate is obtained if a student is declared a graduate (competent) in the implementation of Competency Test. The purpose of this study is to obtain information on the problems being faced by professional nurses who will face the Indonesian National Competency Test through the implementation of Focus Group Discussion (FGD). This type of research is qualitative research with a quasi-experimental research design with one group pretest-posttest design. Stages of Research Methods will be carried out using the design of the quasi-experiment(quasiexperimental) with the target of all nurses in the final semester of totaling 51 people. Data collection method with guided interview guidance. The data analysis method uses dependent $t$-test. Where in the paired groups, the same subject was examined before and after the intervention (design before and after) and at the same time. Based on the results of the t-test calculation, the value of $Z-4,472$ with $(p=0,000)<0.05$ so that the decision of the hypothesis Ha is accepted then $\mathrm{HO}$ is rejected. It was concluded that there was an influence between FGD (Focus Group Discussion) on the Implementation of Competency Tests on the anxiety level of Nurse Profession students at FKK UNPRI Medan in 2019. It is expected that students who will face competency tests to prepare themselves more by following guidance both on campus and outside campus so have good preparation in facing the Competency Test
\end{abstract}

Keywords: Focus Group Discussion, implementation, competence, test, anxiety level

\section{PENDAHULUAN}

Pelaksanaan ujian kompetensi nasional Indonesia dilaksanakan dengan tujuan untuk menyamakan standar mutu lulusan pada setiap institusi pendidikan. Harapan setiap institusi pendidikan adalah seluruh mahasiswa lulus dalam menghadapi ujian kompetensi, namum dibeberapa institusi pendidikan pada kenyataannya tidak seperti apa yang diharapkan. Jumlah kelulusan ujian kompetensi tidak merata di seluruh Indonesia, ada yang jumlah kelulusannya 90-100\% dan ada yang jumlah kelulusannya hanya mencapai 10-30\% pada setiap periode ujian kompetensi. Bagi mahasiswa ujian kompetensi merupakan suatu tantangan 
yang harus dihadapi karena pada saat ini syarat untuk melamar pekerjaan bagi tenaga kesehatan adalah harus memiliki STR (Surat Tanda Registrasi). STR diperoleh apabila seorang mahasiswa dinyatakan lulusan (kompeten) pada pelaksanaan Uji Kompetensi.

Banyak lulusan yang terkendala tidak bekerja karena tidak memiliki STR. Tidak meratanya angka kelulusan peserta Ujian Kompetensi Nasional Indonesia pada setiap institusi pendidikan kesehatan yang ada di Indonesia menjadi suatu permasalahan yang harus diselesaikan dengan segera. Berita terbaru dari seorang pembicara pada acara pelatihan Item Development yang diselenggarakan oleh pihak DIKTI di Batam pada tanggal 27-28 Agustus 2018 mengenai Ujian Kompetensi adalah akan dikeluarkannya surat edaran yang menyatakan bahwa uji kompetensi menjadi syarat exit exam (syarat kelulusan) bagi setiap mahasiswa yang akan diwisuda (diluluskan).

Permasalah tersebut merupakan hal yang sangat mencemaskan bagi mahasiswa profesi ners yang akan menghadapi ujian kompetensi. Kecemasan yang dirasakan oleh mahasiswa Profesi Ners dalam menghadapi Ujian Kompetensi merupakan hal yang perlu ditangani oleh institusi pendidikan. Kecemasan yang berkelanjutan dapat mengakibatkan dampak negatif seperti panik, kebingungan dan gagal memahami sesuatu hal (Ramaiah, 2005). Dampak negatif tersebutakan sangat berdampak buruk bagi mahasiswa profesi ners dalam menghadapi ujian kompetensi.

Jumlah kelulusan ujian kompetensi tidak merata di seluruh Indonesia, ada yang jumlah kelulusannya $90-100 \%$ dan ada yang jumlah kelulusannya hanya mencapai 10-30\% pada setiap periode ujian kompetensi. Focus Group Discussion (FGD) atau diskusi kelompok terarah adalah suatu proses pengumpulan informasi terhadap suatu permasalahan tertentu yang sangat spesifik melalui diskusi kelompok. Adapun yang menjadi tujuan dari pelaksanaan FGD adalah untuk memperoleh masukan maupun informasi mengenai suatu permasalahan yang bersifat lokal dan spesifik, sehingga institusi pendidikan mendapatkan cara yang lebih tepat untuk mengatasi yang dihadapi oleh mahasiswa (Irwanto, 2006). Diharapkan dengan dilaksanakan FGD ini maka institusi pendidikan dapat menemukan informasi tentang permasalahan yang sedang dihadapi oleh 
mahasiswa dalam mengikuti ujian komptensi. Tujuan penelitian adalah untuk mengetahui pengaruh focus group discussion tentang pelaksanaan uji kompetensi terhadap tingkat kecemasan mahasiswa profesi ners.

\section{METODE PENELITIAN}

Jenis penelitian ini adalah penelitian kuantitatif desain penelitian quasi experimental dengan rancangan one group pretest-posttest. Penelitian ini dilaksanakan di FKK UNPRI Medan, dikarenakan jumlah kelulusan mahasiswa profesi ners pada saat uji kompetensi masih sangat rendah antara 10-20\% pada setiap pelaksanaan.

Populasi dalam penelitian ini adalah mahasiswa Profesi Ners Fakultas Keperawatan dan Kebidanan Universitas Prima Indonesia yang akan menghadapi ujian kompetensi nasional Indonesia. Teknik pengambilan sampel dalam penelitian ini dengan menggunakan teknik sampling jenuh berjumlah 51 mahasiswa. Instrumen pengumpulan data dengan menggunakan Hamilton Rating Scale for Anxiety (HARS). Metode analisis data menggunakan uji-t pada kelompok berpasangan, subjek yang sama diperiksa sebelum dan setelah intervensi (desain before dan after) dan waktu bersamaan.
Kegiatan FGD menggunakan panduan pelaksanaa dan Panduan wawancara terpimpin, dilakukan terhadap seluruh mahasiswa profesi ners semester akhir dengan periode pelaksanaan FGD tiga kali. Setiap pelaksanaan FGD dalam waktu 1 - 1,5 jam. Setiap pelaksanaan FGD dipimpin oleh 1 moderator, 1 notulen, 1 pengembangan peserta dan 2 orang logistik.

\section{HASIL PENELITIAN}

\section{Analisa Univariat}

Berikut ini hasil analisis univariat diperlihatkan pada tabel berikut:

Tabel 1 Distribusi Frekuensi Tingkat Kecemasan Sebelum dilakukannya FGD (Focus Group Discussion) kepada Mahasiswa Profesi Ners FKK UNPRI Medan

\begin{tabular}{|c|c|c|c|}
\hline No & $\begin{array}{l}\text { Kecemasan } \\
\text { pre-test }\end{array}$ & $\begin{array}{c}\text { Jumlah } \\
\text { (n) }\end{array}$ & $\begin{array}{c}\text { Persentase } \\
(\%)\end{array}$ \\
\hline 1 & $\begin{array}{l}\text { Kecemasan } \\
\text { ringan }\end{array}$ & 3 & 6 \\
\hline 2 & $\begin{array}{l}\text { Kecemasan } \\
\text { sedang }\end{array}$ & 18 & 35 \\
\hline 3 & Kecemasan & 26 & 50 \\
\hline \multirow[t]{2}{*}{4} & Berat/Panik & 4 & 9 \\
\hline & Total & 51 & 100 \\
\hline
\end{tabular}

Berdasarkan tabel di atas skala cemas sebelum dilakukan FGD dapat dilihat bahwa dari 51 siswa mayoritas berada pada tingkat kecemasan berat yaitu sebanyak 26 siswa (50\%) dan minoritas mengalami skala kecemasan ringan yaitu sebanyak 3 siswa (6\%). 
Tabel 2 Distribusi Frekuensi Tingkat Kecemasan Setelah dilakukannya FGD (Focus Group Discussion) kepada mahasiswa profesi ners FKK UNPRI Medan

\begin{tabular}{clcc}
\hline No & Kecemasan post-test & $\begin{array}{c}\text { Jumlah } \\
(\mathbf{n})\end{array}$ & $\begin{array}{c}\text { Persentase } \\
(\mathbf{\%})\end{array}$ \\
\hline 1 & Kecemasan ringan & 2 & 4 \\
2 & Kecemasan sedang & 38 & 74 \\
3 & Kecemasan & 10 & 20 \\
4 & Berat/Panik & 1 & 2 \\
\hline & Total & $\mathbf{5 1}$ & $\mathbf{1 0 0}$ \\
\hline
\end{tabular}

Sedangkan setelah dilakukan FGD skala kecemasan siswa mayoritas berada skala kecemasan sedang sebanyak 38 orang $(74 \%)$ dan minoritas berada pada skala kecemasan panik sebanyak 1 siswa $(2 \%)$.

\section{Analisa Bivariat}

Setelah pelaksanaan FGD selesai, selanjutnya dilakukan analisis bivariat.

Tabel 3 Pengaruh FGD (Focus Group Disscusion) tentang Pelaksaanaan Uji Kompetensi terhadap Tingkat Kecemasan Mahasiswa Profesi Ners Tahun 2019

\begin{tabular}{cccccccccc}
\hline & \multicolumn{3}{c}{ Skala Kecemasan } & N & Mean & $\begin{array}{c}\text { Std. } \\
\text { Deviation }\end{array}$ & Z & $\begin{array}{c}\text { P- } \\
\text { Value }\end{array}$ \\
\cline { 2 - 10 } FGD & R & S & B & P & & & & & \\
\hline Pre test & 3 & 18 & 26 & 4 & 20 & 3.60 & 0,940 & -4.472 & 0,000 \\
Post test & 2 & 38 & 10 & 1 & 20 & 2.60 & 0,940 & & \\
\hline
\end{tabular}

Berdasarkan tabel 3 diatas dapat dilihat bahwa dari 51 siswa Profesi Ners Jika nilai signifikansi $>0.05$, maka $\mathrm{H}_{0}$ diterima dan Jika signifikasi $<0.05$, maka $\mathrm{H}_{0}$ ditolak. Berdasarkan hasil perhitungan uji t-test, maka nilai $\mathrm{Z}$ 4.472 dengan $(p=0.000)<0.05$ sehingga keputusan hipotesis maka $\mathrm{H}_{0}$ ditolak. Disimpulkan bahwa ada pengaruh FGD (Focus Group Discussion) tentang pelaksanaan uji kompetensi terhadap tingkat mahasiswa profesi ners tahun 2019.

\section{PEMBAHASAN}

\section{Skala Kecemasan Sebelum Dilakukannya FGD}

Berdasarkan hasil penelitian sebelum dilakukan FGD dapat dilihat bahwa dari 51 siswa mayoritas berada pada tingkat kecemasan berat yaitu sebanyak 26 siswa (50\%) dan minoritas mengalami skala kecemasan ringan yaitu sebanyak 3 siswa (6\%). 
Menurut Lubis

(2009)

menjelaskan bahwa kecemasan adalah tanggapan dari sebuah ancaman nyata ataupun khayal. Kecemasan dialami ketika berfikir tentang sesuatu tidak menyenangkan yang akan terjadi. Kecemasan adalah suatu perasaan yang sifatnya umum, dimana seseorang merasa ketakutan atau kehilangan kepercayaan diri yang tidak jelas asal maupun wujudnya (Wiramihardja, 2005). Asumsi peneliti adalah kecemasan yang dihadapi mahasiswa dalam menghadapi Uji Kompetensi Nasional Indonesia di FKK UNPRI Medan adalah suatu kondisi yang terjadi akibat kurangnya persiapan dalam menghadapi ujian tersebut. Hal ini terlihat dari beberapa pertanyaan yang diajukan oleh peneliti pada saat FGD diperoleh data bahwa mahasiswa masih kurangnya informasi tentang pelaksanaan bimbingan UKOM (uji kompetensi) dan mahasiswa masih kurang banyak dalam membahas soal UKOM. Mahasiswa juga merasa cemas karena masih belum pernah menghadapi try-out UKOM.

\section{Skala Kecemasan Setelah Dilakukannya FGD}

Berdasarkan hasi lpenelitian setelah dilakukan FGD skala kecemasan siswa mayoritas berada skala kecemasan sedang sebanyak 38 siswa (74\%) dan minoritas berada pada skala kecemasan panik sebanyak 1 siswa (2\%). Menurut teori pada dasarnya setiap individu yang sedang mengalami tingkat kecemasan yang tinggi seringnya akan berdampak negatif seperti: panik, kebingungan dan gagal memahami sesuatu hal (Ramaiah, 2005).

Asumsi peneliti adalah setelah dilakukannya FGD peneliti menemukan data bahwa kecemasan mahasiswa ratarata menurun. Ternyata FGD membawa pengaruh terhadap kecemasan mahasiswa Profesi Ners FKK UNPRI Medan. Melalui FGD peneliti juga menemukan beberapa permasalahan yang sedang dihadapi mahasiswa dan moderator FGD telah memberikan beberapa saran dan masukan kepada mahasiswa saat akan mengahadapi Ujian Kompetensi.

\section{Pengaruh FGD (Focus Group Disscusion) tentang Pelaksaanaan Uji Kompetensi terhadap Tingkat Kecemasan Mahasiswa Profesi Ners Tahun 2019}

Berdasarkan hasil penelitian setelah dilakukannya FGD diperoleh data bahwa dari 51 mahasiswa yang diuji apabila nilai signifikansi $>0.05$, maka $\mathrm{H}_{0}$ diterima, dan apabila nilai signifikannya $<0.05$ maka Ha diterima. Berdasarkan hasil perhitungan uji t-test, maka nilai $\mathrm{Z}$ 
- 4.472 dengan $(\mathrm{p}=0.000)<0.05$ sehingga keputusan hipotesis maka $\mathrm{H}_{0}$ ditolak. Disimpulkan bahwa ada pengaruh FGD (Focus Group Discussion) tentang pelaksanaan uji kompetensi terhadap tingkat mahasiswa profesi ners tahun 2019.

Focus Group Discussion (FGD) atau diskusi kelompok terarah adalah suatu proses pengumpulan informasi terhadap suatu permasalahan tertentu yang sangat spesifik melalui diskusi kelompok. Adapun yang menjadi tujuan dari pelaksanaan FGD adalah untuk memperoleh masukan maupun informasi mengenai suatu permasalahan yang bersifat lokal dan spesifik, sehingga institusi pendidikan mendapatkan cara yang lebih tepat untuk mengatasi yang dihadapioleh mahasiswa (Irwanto, 2006). Diharapkan dengan dilaksanakan FGD ini maka institusi pendidikan dapat menemukan informasi tentang permasalahan yang sedang dihadapi oleh mahasiswa dalam mengikuti ujian komptensi.

Penelitian yang sama dilakukan oleh Aprilia (2016) dengan judul penelitian "Efektivitas Focus Group Discussion untuk Mengurangi Stres Pada Siswa SMA yang Akan Menghadapi Ujian Nasional” menjelaskan bahwa pelaksanaan FGD terbukti efektif dalam mengurangi stres pada anak SMA yang akan menghadapi Ujian Nasional. Penelitian Budi (2017) tentang: pengaruh situasional terhadap kecemasan mahasiswa D III keperawatan dalam menghadapi ujian skill laboratorium menjelaskan bahwa mahasiswa D III Keperawatan yang akan menghadapai ujian skill laboratorium sering mengalami kecemasan. Dengan dilaksanakannya FGD pada mahasiswa DIII Keperawatan yang akan mengikuti ujian dapat menurunkan kecemasan mahasiswa DIII Keperawatan.

Asumsi peneliti terhadap pelaksanaan FGD adalah FGD sangat perlu dilaksanakan guna memperoleh data terhadap permasalahan apa yang sedang dihadapi oleh mahasiswa pada saat akan menghadapi ujian kompetensi, dengan diperolehnya data tersebut akan dapat digunakan dalam membuat suatu rencana untuk meningkatkan jumlah lulusan mahasiswa profesi ners FKK UNPRI Medan. Pelaksanaan FGD juga membawa dampak terhadap penurunan tingkat kecemasan mahasiswa dalam menghadapi Ujian Kompetensi Nasional Indonesia. 


\section{KESIMPULAN}

Sebelum dilakukan FGD (pretest), rata-rata skala kecemasan siswa dengan kategori kecemasan berat. Sesudah dilakukan FGD (post-test), ratarata skala kecemasan dengan kategori kecemasan ringan. Ada pengaruh FGD (Focus Group Discussion) tentang pelaksanaan uji kompetensi terhadap tingkat kecemasan mahasiswa profesi Ners

\section{SARAN}

Bagi intitusi pendidikan agar lebih memberikan motivasi dan bimbingan untuk mempersiapkan mahasiswa dalam menghadapi Uji Kompetensi sehingga dapat mengurangi tingkat kecemasannya. Diharapkan kepada mahasiswa agar lebih banyak mempersiapkan diri dengan mengikuti bimbingan dikampus dan diluar kampus sehingga memiliki persiapan yang matang dalam mengahadapi Uji Kompetensi.

\section{UCAPAN TERIMA KASIH}

Terima kasih kepada

Kementerian Riset, Teknologi, dan Pendidikan Tinggi yang telah memberikan kesempatan untuk mendapatkan hibah penelitian Dosen Pemula (PDP) dan Kepada LPPM UNPRI yang telah memfasilitasi peneliti dalam melaksanakan penelitian ini sampai selesai.

\section{Daftar Pustaka}

Aprilia, D.(2016). Efektivitas Focus Group Discussion untuk Mengurangi Stres Pada Siswa SMA yang Akan Menghadapi Ujian Nasional. Jurnal Studia Insania.

Budi, Y. S., Wardaningsih, S., \& Afandi, M. (2017). Pengaruh situasional terhadap Kecemasan Mahasiswa DIII Keperawatan Dalam Menghadapi Ujian Skill Laboratorium. Tesis.

Irwanto. (2006). Focus Group Discussion (FGD) Sebuah Pengantar Praktis. Jakarta: Pusat Kajian Pembangunan Masyarakat Universitas Katolik Indonesia Atma Jaya

Lubis, M. N. (2009). Depresi: Tinjauan Psikologis. Jakarta: Kencana Prenada Media Group

Permenristekdikti. (2016).UndangUndang No. 12. Tentang Uji Kompetensi Nakes.

Pedak, M. (2009). Metode Supernol Menaklukkan Stres. Jakarta: Hikmah.

Savitri., R. (2005). Kecemasan. Jakarta: Bhuana Ilmu Populer.

Wiramihardja., S. (2005). Pengantar psikologi Abnormal. Bandung: PT Refika Aditama

Laksana, I. M. A. D. (2018). FGD untuk Prokratinasi Akademik pada Siswa Sekolah Menengah Pertama. Skripsi.

Nursalam. (2013). Metodologi Penelitian Ilmu Keperawatan: 
Pendekatan Praktis: Jakarta: Salemba Medika.

Notoatmodjo, S. (2010). Metodologi Penelitian Kesehatan. Jakarta: Rineka Cipta.

Maierw, Buller R, Philipp M, Heuser, I. Skala kecemasan Hamilton: keandalan, paliditas dan sensitivitas terhadap perubahan kecemasan dan gangguan depresi. J AFF ect disord 1988; 14 (1): $61-8$ 